\title{
Is Supervision Keeping Pace with Innovation?*
}

\author{
Jaime Caruana \\ Governor Banco de España, C/Alcalá, 48, 28014 Madrid, Spain. \\ E-mail: jclgovjl@bde.es \\ Chairman, Basel Committee on Banking Supervision
}

In this paper, the author argues that financial supervision is keeping up with the pace of innovation in the industry by virtue of what he calls a "virtuous circle": the supervisory framework is aligning itself more and more with the best risk management practices, while at the same time encouraging further advances in those practices. In the long run, financial stability would benefit businesses, consumers and financial institutions.

The Geneva Papers (2005) 30, 11-18. doi:10.1057/palgrave.gpp.2510022

While The Geneva Association and the Basel Committee on Banking Supervision hail from different Swiss cities and different sectors of the financial services industry, both organizations monitor trends in risk management and work to encourage advances in that discipline. This is a difficult but enormously important duty for all of us. Financial organizations - whether they are banks, securities firms, or insurance companies - seek constantly to tailor products and services to the ever-changing needs of their customers. To succeed in an environment marked by rapid evolution and continuous innovation, financial services providers must understand thoroughly the benefits and costs of their current activities as well as those of proposed new activities. At the same time, they must watch the horizon carefully for future trends that might alter the balance between risks and rewards. Supervisors, for our part, must ensure that the regulatory system encourages banks, securities firms, and insurance companies to be capable of managing their risks today and be ready to respond to new challenges tomorrow.

This raises an important question: is financial supervision keeping up with the pace of innovation and change in the industry? The answer, I believe, is "yes". Risk management and the supervisory system cannot and should not evolve independently of each other. Indeed, the constructive dialogue underway today between supervisory agencies and financial services providers is helping to create a "virtuous circle": the supervisory framework is becoming more closely aligned with the best risk management practices in use, while at the same time encouraging further advances in those practices.

To help explain the story of the virtuous circle, this article will summarize three developments.

- First, a recent study suggests that leading financial institutions around the world are developing more rigorous and comprehensive risk management approaches.

\footnotetext{
* This article is based on Mr. Caruana's address to the 31st General Assembly of the Geneva Association on 27 May 2004 in Madrid. The opinions expressed are the author's own and do not necessarily reflect the views of the Bank of Spain or those of the Basel Committee on Banking Supervision or its member organisations.
} 
These developments allow institutions to adopt more integrated approaches to risk management across very different business lines and, at the same time, are enabling firms to get a sense of the aggregate amount of risk they face.

- Second, supervisors have sought to incorporate these more rigorous and comprehensive risk management approaches into the regulatory structure. We are moving toward a more flexible and forward-looking approach to financial supervision that seeks to motivate prudent management - and thereby complete the "virtuous circle" - by encouraging further advances in risk management. This reform is especially evident in the banking world under the Basel Committee's "Basel II" framework, which revises the standards for bank capital adequacy. ${ }^{1}$ Likewise, work is under way in the insurance area, thanks to the discussions being led by the International Association of Insurance Supervisors (IAIS), on a supervisory framework that would apply to all insurance regulatory systems globally.

- Evolution in risk management and the reform of financial supervision should complement and reinforce each other, but both are influenced as well by the important revisions being made to accounting guidelines. The Geneva Association has taken a great interest in this topic, and this note concludes with my thoughts on the convergence of accounting standards, advances in risk management, and supervision.

\section{Risk management trends across financial services sector}

The story of the "virtuous circle" begins with the work under way in the private sector to improve the quality of risk management. One recent study ${ }^{2}$ conducted by the "Joint Forum" - a body representing major financial supervisory agencies from the Basel Committee, the International Organization of Securities Commissioners (IOSCO), and the IAIS - identified two key emerging trends in risk management practices in the financial services sector. From its survey of practices under way at 31 large, complex firms engaged in banking, securities, or insurance, or in some mix of these activities in 12 jurisdictions, the Joint Forum found that leading organizations (a) are increasingly integrating their risk management functions across the firm and (b) are working to aggregate their separate measures of risk used in individual business lines into a single, firm-wide measure of risk.

\section{Integration of risk management}

One of the most notable advances in risk management across all three financial services sectors is the growing emphasis on developing a firm-wide assessment of risk, which constitutes the first trend in the Joint Forum's report.

Improvements in technology and telecommunications have made it easier for firms to gather, collect, and analyse large amounts of data on their exposures and business activities efficiently and increasingly in near "real time". To make the best use of

\footnotetext{
${ }^{1}$ The Basel Committee on Banking Supervision (June 2004).

${ }^{2}$ The Joint Forum (August 2003).
} 
firm-wide data, some organizations have established a dedicated risk management function to foster more highly integrated and systematic approaches to risk measurement and management. The risk management function typically promotes the use of common risk measures across business lines. It can then report the firm-wide risk data to senior management. Reports may range from daily updates on "value-atrisk" trading positions to regular, if less frequent, compilations of the results of stress testing.

The broader use of shared definitions to guide the comprehensive reporting of risk across the firm enables the risk management function to identify concentrations of risk. Concentrations matter particularly when various business lines within the firm have different kinds of exposures to the same counterparty. Comprehensive and consistent reporting helps, moreover, to ensure that the firm is aware of the wide range of risks to which it is exposed, that it understands the relative importance of various risks and how they may interact, and that the firm is less likely to ignore material sources of risk.

The Joint Forum's study suggests that no single model for organizing an integrated risk management function has become dominant. In some financial organizations, the function may exercise a considerable degree of control over individual businesses. In others - and especially in insurance companies - local business units continue to operate autonomously to a great degree.

Yet nearly all firms that establish integrated risk management units are highly dependent on the quality of their information technology to collect, analyse, and report firm-wide data efficiently and effectively. Some participants have found that the greatest challenge in developing a centralized risk management structure lies in constructing compatible and efficient management information systems across all of their businesses. As a result, they devote substantial resources in terms of personnel and expenditures to the maintenance and enhancement of their management information systems.

\section{Risk aggregation}

Collecting risk data across many business lines has catalysed further efforts to aggregate those measures of risk by quantifying them in a more rigorous and more consistent fashion. This is the second major risk management trend identified in the Joint Forum report. The quantification of risk is not a new concept. In the insurance industry, for instance, actuaries have long sought to estimate the likelihood of various events taking place. What is new is that, in recent years, financial risk managers and researchers apply mathematics, statistics, and modelling to many risk exposures that were previously not thought to be readily quantifiable.

In the banking industry, for example, statistical and computational analyses developed for evaluating exposures to market risk led, over the past decade or so, to the application of similar techniques to credit risk. As we will see, the introduction of increasingly reliable estimates of the drivers of credit risk, such as the probability of default, led to many of the proposals that form the basis for the new Basel II bank capital framework. 
The Joint Forum found that the "ultimate expression" of risk aggregation is the summation of many types of risk into a single risk measure. This measure, often called "economic capital", estimates the amount of capital a firm requires to protect itself against all risks with a certain degree of confidence. The benefits of developing more aggregated measures of risk across diverse business lines are especially appealing to complex financial organizations whose activities span many kinds of activities. As a result, it is not surprising that large, mixed financial conglomerates have tended to invest the most in the development of economic capital estimates.

\section{Financial supervision}

The two trends in the financial services sector to integrate risk management into a dedicated function and to aggregate risk measures into a single measure of economic capital begin the "virtuous circle". These trends are influencing much more than the behaviour of individual firms. They are similarly influencing the policy and practice of financial supervision, which in turn seeks to promote further improvements in risk management practices. This helps to complete the circle and to begin another cycle of advances.

In the insurance sector, this movement is visible in the European Union's "Solvency II" project. The IAIS's initiative to establish a new international insurance regulatory framework will likewise be significant to the industry in the new future. But certainly a lot of attention has been paid to the work that the Basel Committee and other supervisors have been undertaking to reform the international bank capital adequacy framework under Basel II.

Basel II represents one of the most important reforms in banking supervision. For almost 6 years, central bankers, bank supervisors, and the industry have been discussing ways to revise the 1988 Basel Accord, which constitutes a cornerstone of the bank regulatory framework. The 1988 Accord was a landmark achievement in its own right. It represented the first internationally accepted "yardstick" for determining the adequacy of a bank's capital. It was relatively simple to apply and, perhaps as a result of its simplicity, was adopted by supervisors in over 100 countries.

But its simplicity may have led in some ways to its gradual decrease in relevance for sophisticated banks and systems. Leading banks made substantial improvements in their measures of risk. As the Joint Forum reported, industry leaders introduced integrated risk management functions and raised their standards for quantifying and aggregating various risks. Extraordinary growth in practices such as securitization and in the use of sophisticated derivative products allowed banks to transfer credit risk in ways that the 1988 Accord does not capture. In addition, some banks began to manage their exposures to operational risk separately and as a comprehensive practice comparable to the management of credit or market risk.

By the late 1990s, it became increasingly clear to leading banks and their supervisors that the original Accord no longer provided meaningful measures of risk for the most sophisticated banking organizations. As a result, the Basel Committee and others began to discuss ways to revise the existing capital rules to account for these advances. 
Supervisors sought more than a simple revision of the existing framework. We wanted to align our capital requirements more closely with the best measures of economic risks that banks actually face. We sought, furthermore, to fortify the stability of the banking sector so that banks could continue to serve as a source of credit through good years and bad. In our view, promoting financial stability will benefit not just banks, but also other businesses and consumers as well.

To incorporate the latest advances in risk management and to develop a more forward-looking approach to supervision, the Basel Committee embraced a "threepillar" approach to capital requirements. Rather than simply setting out a static minimum requirement for capital levels, the new capital framework will rely on three mutually reinforcing policy approaches. They consist of: first, risk-sensitive minimum requirements; second, a system of supervisory review; and, third, enhanced transparency and market discipline. Each of these three pillars offers unique benefits on its own, but the real strength of the three pillars stems from their ability to complement each other.

\section{Pillar 1: Minimum capital requirements}

The first pillar - which specifies the minimum capital requirements - constitutes a very direct approach to supervision. By applying a uniform set of rules to banks, the first pillar adds transparency to the regulatory process. Applying a shared set of rules to all banks makes it easier to compare organizations and get a sense of their relative degrees of solvency.

On a technical level, the Committee based the measures of risk on the advanced practices that banks are adopting. The rules reflect the evolution in credit risk management by allowing qualifying banks to rely partly on their own estimates of the drivers of credit risk to determine the amount of capital required against particular exposures. One such driver of credit risk might be the bank's own estimate of a borrower's probability of default. Similarly, the new capital rules will reflect the advances in operational risk measurement by incorporating an explicit capital charge for such exposures to loss.

So the minimum rules will align capital charges more closely to better measures of the actual underlying economic risks that the industry is developing. Furthermore, to encourage those institutions that are not at the leading edge in this field to make enhancements in their internal controls and risk management processes, Basel II will offer explicit economic incentives to adopt, over time, more accurate measures of risk and more sophisticated means for controlling their exposures to such risks.

However, the Basel Committee recognized that relying on uniform rules alone would have introduced certain drawbacks. Rules tend to be inflexible and therefore might preclude or ignore innovation. Applying uniform rules may also fail to account for a bank's unusual businesses or risk profiles.

Pillar 2: Supervisory review

Consequently, our second pillar, supervisory review, addresses some of those drawbacks. It introduces judgement into the policy mix. Banks and supervisors will 
exercise discretion in determining capital needs relevant to their particular businesses and risk profiles. That degree of discretion makes the supervisory framework more flexible and better able to adapt to change and innovation. In a way, one might think of the second pillar as being analogous to the "principles-based" policy approach that some have advocated in accounting and financial reporting. We have also established processes to ensure that the flexibility and discretion afforded by Pillar two is exercised in a consistent way.

\section{Pillar 3: Market discipline}

The third pillar, market discipline, adds greater transparency to the process. When a bank discloses information that offers meaningful insight into its risk positions and exposures, marketplace participants are better able to assess its financial health. Counterparties, investors, rating agencies, and even customers can reward banks that manage their risks properly and penalize those that hold unrealistically low amounts of capital for their risk. Their reactions provide economic incentives for banks to strengthen their management of risk and hold at least adequate levels of capital against their risks.

One might say that Basel II seeks an "efficient frontier" of policy objectives through the three pillars. Each pillar provides something that the other two cannot. Each is essential to achieving our overall objective of financial stability. The analogy of the three pillars as a portfolio of policy options may be an oversimplification. However, it helps one to visualize why supervisors think that the most "efficient frontier" involves a mixture of minimum rules, tempered by supervisory discretion, and supplemented by market-based incentives.

\section{Accounting, risk management, and supervision}

Of course, the three-pillar supervisory system is highly dependent on a firm's internal measures of risk exposures. Basel II, for example, looks at a bank's own measures of risk in Pillar 1. Supervisors then engage bank managers in a dialogue on their interpretations of those measures - and the steps managers take in response - in Pillar 2. Finally, Pillar 3 is intended to give the market greater insight into those measures of risk exposures and what the bank may do to control them. Because the three pillars are so dependent on the internal measures, neither supervisors nor bankers can ignore the mechanics that define how financial data are recorded and reported. Those mechanics are governed by national accounting standards, themselves prone to change as standards-setters seek greater convergence in accounting rules, which is the final development this note will address.

Supervisors and global market participants face significant hurdles in exercising discipline on an entity whose operations span more than one jurisdiction. Business practices differ between countries. Legal systems may be unfamiliar. Deciphering balance sheets prepared under national accounting systems can be an extremely taxing undertaking.

Considering those burdens alone, it is easy to agree that supervisory and market discipline would be more effective under more harmonious - if not completely 
harmonized - accounting rules. Yet the task of converging on one set of accounting rules across jurisdictions is formidable.

In our duty to safeguard and reinforce financial stability, central banks and financial supervisors have a legitimate interest in the quality of accounting standards and their effective implementation. We have three concerns. First, I believe that in order to help fortify the financial system, accounting standards should support - or at least be consistent with - sound risk management and control practices in use in the industry.

Secondly, accounting standards should facilitate market discipline by providing a more transparent "window" into an organization's financial position and performance and likewise into its measures and management of risk exposures. Only when marketplace participants have greater insight into these matters can they make informed decisions that, in turn, create incentives for prudent behaviour.

Thirdly, accounting standards should facilitate the effective supervision of financial institutions. In the specific case of the insurance industry, I think agreement exists that, for international standards to be complete, we need a single, high-quality standard developed to address insurance liabilities. The challenge lies in specifying a model that fits together seamlessly with other international accounting guidelines and at the same time aligns well with sound insurance risk management and supervisory objectives. Given some of the issues we have faced in other areas of accounting, that seems unlikely to be a quick or easy job.

The three issues I have mentioned above explain why financial supervisors, and especially the Basel Committee, attach great importance to playing an active role in the international debates on accounting. In the Basel Committee's case, we seek to represent the supervisory perspective on key accounting issues relevant to banking, and we support the work under way in the accounting profession towards convergence in accounting standards globally.

With regard to Basel II, the Committee worked closely with our colleagues in the International Accounting Standards Board to avoid conflicts between Pillar 3 and the broader accounting standards. In fact, the Committee views Pillar 3 as a further refinement of the accounting standards that apply to banks' specific exposures. Because we recognize that we have much to do in this area, we will continue to monitor accounting and market developments in the light of Pillar 3. Our dialogue with accounting standards-setting bodies and the accounting profession will continue to grow in the years to come.

\section{Working toward greater financial stability}

Clearly, the practices of risk management and supervision must keep pace with changes in accounting practices, and the work we have to undertake in all three areas risk management, supervision, and accounting - is quite demanding. To develop new ways of thinking about risk and about the techniques for measuring it, we will require hard research and significant resources. We must gather and pore over large amounts of data to sharpen our understanding of various risks and their relationships to each other. We must dedicate our talent, staff, and indeed funds to undertake this work. I 
believe it to be equally demanding to develop a supervisory structure that capitalizes on - and further encourages - those advances. This is especially true when trying to implement a shared framework in a manner that is consistent between jurisdictions yet still flexible enough to keep pace with advances in the state of the art in risk management.

The benefits of doing so are many. On a microeconomic level, the virtuous circle described in this note should help individual firms to improve the quality of their controls in the short run and strengthen their competitiveness in the long run. Yet we supervisors are especially motivated by the benefits we expect at the macro level. We believe that, when all financial institutions have the right incentives to pursue profits responsibly, the financial services sector becomes better managed, more resilient, and better able to serve as a source for sustainable growth for the economy. Improving the stability of the financial sector would clearly benefit businesses, consumers, and financial institutions alike. It is for these reasons that the efforts of marketplace participants and financial supervisors must complement and reinforce each other to work toward greater financial stability.

\section{References}

The Basel Committee on Banking Supervision (2004) International Convergence of Capital Measurement and Capital Standards: a Revised Framework (June), Bank for International Settlements, Basel (http:// www.bis.org/publ/bcbsca.htm).

The Joint Forum (2003) Trends in Risk Integration and Aggregation (August), Bank for International Settlements, Basel (http://www.bis.org/publ/joint07.htm).

\section{About the author}

Jaime Caruana has been governor of the Banco de España and a member of the Governing Council of the European Central Bank since 2000. In May 2003, he succeeded William McDonough as Chairman of the Basel Committee on Banking Supervision. Before that, Mr. Caruana worked in the Spanish private sector; among other positions, he was managing director of an investment service company from 1987 to 1991 and chairman of a fund management company from 1991 to 1996. Subsequently, he served as a senior official in the Spanish Treasury and Ministry of Trade. Early in his career, he was posted as Commercial Attaché in the Spanish Commercial Office in New York. Mr. Caruana has a degree in telecommunications engineering from the Universidad Complutence de Madrid. He is also a qualified economist and has authored several publications and articles on the Spanish financial system, government financing and public debt. 